\title{
Study of the Impact and Mechanism of Gypsum Binder Hydration Process in the Presence of Nanomodifiers
}

\author{
Victor Derevianko ${ }^{\mathrm{a}}$, Natalia Kondratieva ${ }^{\mathrm{b}}$, Hanna Hryshko ${ }^{\mathrm{c}}$, \\ ${ }^{a}$ Department of Construction Materials, Products and Structures Engineering, State Higher \\ Educational Establishment "Prydniprovs'ka State Academy of Civil Engineering and \\ Architecture”, 24-a Chernyshevsky St., 49600 Dnipro, Ukraine \\ ${ }^{\mathrm{b}}$ Department of Chemical Engineering and Binding Materials, Ukrainian State University of \\ Chemistry and Chemical Technology, 8 Haharin Ave., 49005 Dnipro, Ukraine \\ $c^{*}$ Department of Hydroreclamation Systems Operation and Construction Technology, Dnipro State \\ University of Agriculture and Economics, 25 Voroshylov St., 49600 Dnipro, Ukraine \\ e-mail: gryshko.anna0101@gmail.com
}

Keywords: carbon nanotubes, calcium sulfate hemihydrate, modification, hydration, calcium sulfate matrix.

This article represents the results of the research of nanomodification of mineral binders involving structure formation mechanisms and gypsum binder hydration process, and thus, affecting various properties. Experiments proved that during growth, crystals partly penetrate into each other and form a three-dimensional network permeating and incorporating the entire gypsum stone into a whole body, which promotes structuring of calcium sulfate matrix and improvement in gypsum compressive strength up to $30 \%$. Chemical functionalization of the surface of carbon nanotubes promotes a reduced sedimentation effect, allows for a more uniform nanostructure dispergation throughout the modified material volume and provides chemical interaction between the substance matrix and nanotubes.

\section{Introduction}

Currently, reserves for the improvement of properties of materials by using conventional methods have been substantially used up.

One of the biggest challenges for the $21^{\text {st }}$ century is the development of nanostructures with adjustable parameters and tailored properties. The most exciting research area is nanostructured materials science [1-3].
Nanomaterials in construction is a very relevant topic, which is confirmed by research funding in developed countries in 2015: USA 4.5 billion USD; Japan - 2.3 billion USD; Germany -1.8 billion USD; Russia -0.5 billion USD; and Ukraine -0.08 billion USD.

International information resources do not provide any information on funding for nanotechnologies in Ukraine's construction 
industry. However, it should be noted that research studies are being conducted. Example: FED, Kharkiv Plant; Malyshev Plant; Motor Sich, Zaporizhzhia; HIIT Medical Center; Kyiv State Academy of Civil Engineering and Architecture. For instance, NANONAT-Eps research and development laboratory and shop are in operation at the FED Plant.

In November 2013, a pilot project (NANONAT-EPS) on support of nanotechnology development in Europe (European Partnership countries (EPS) Frantsevitch Institute on Problems of Materials Science (IPMS)) was initiated in Kyiv (Ukraine).

In 2015, a Ph.D. thesis "Structureformation role of carbon nanostructures in composite materials" was defended in the Prydniprovs'ka State Academy of Civil Engineering and Architecture (PGASA).

The literature review conducted by the authors showed unavailability of reliable information on the mechanisms of mineral binding substances hydration processes in the presence of nanomodifiers. Laboratory research studies have confirmed that there are minor changes in the physical and mechanical properties. Lack of adapted research methodology, state-of-the-art equipment and materials complicate the problem.

Therefore, research studies focused on investigating the impact and mechanism of gypsum binder hydration process in the presence of nanomodifiers remain relevant.

There isn't any certain clarity so far in respect of the hydration process mechanism. There is a basic assumption stating that carbon nanoparticles (CNP) and carbon nanotubes (CNT) are crystallization nuclei due to the interphase region extension.

A challenging issue involves modifier dispergation throughout the binder volume and its impact on the hydration process, structure and properties.

In addition, there is an apparent lack of systems and technology solutions in this field as well as practices for handling nanomaterials. Another challenging problem is the availability of state-of-the-art equipment. We need to seek help from foreign colleagues, which extends the research period.

The research purpose is to investigate the impact on the mechanism of gypsum binder hydration process in the presence of nanomodifiers. During the research, the following targets were identified: 1. To investigate modifier dispergation throughout the binder volume and its impact on the hydration process, structure and properties. 2. To investigate the impact and mechanism of gypsum binder hydration process in the presence of nanomodifiers.

\section{Experimental part}

The research involves scanning methods, methods of X-ray phase analysis and 
calorimetric tests. Methods of X-ray phase analysis and calorimetric tests were used to investigate mineral composition and kinetics of processes occurring in a modified matrix. Structure, size and morphology of newgrowths were investigated by using scanning electron microscopes. The following materials were used for the research: carbon nanoparticles (CNPs), carbon nanotubes (CNTs), and functionalized nanotubes $(\mathrm{OH}-\mathrm{CNTs}, \mathrm{COOH}-\mathrm{CNTs}) . \quad$ To improve the performance of carbon nanotubes (CNTs) the surface of CNTs was chemically modified with functional groups such as hydroxyl or carboxylic groups [4]. Carboxylation is the interaction with oxidizing functional reactants (nitric acid, chromium salts, and hydrogen peroxide). Carboxylation was carried out by the interaction of nanotubes with various oxidizing agents [4 - 6] (chromium and manganese salts at maximum oxidation states, hydrogen peroxide). For the oxidization of CNTs by hydroxyl groups, a mechanochemical method [7-8] was used; the method involves milling of CNTs together with alkali within 60 minutes.

Building gypsum was used as a binder.

A gypsum binder with the addition of a surfactant in the amount of $0.4 \%$ was used as a reference standard. Polycarboxylate P-11 from Macromer Research and Development Enterprise (Vladimir, Russia) and Sika Retarder plasticizer (Switzerland) were used as plasticizers. The suspension preparation process was controlled by the parameters as follows: suspension density, colloidal system stability (evaluation of zeta potential [8]), CNT concentration, and viscosity.

At the initial stage, we investigated modifier dispergation throughout the binder volume and its impact on the hydration process, structure and properties.

The dispergation was conducted in the media as follows: CNTs-water. CNTs were added to a plasticizer-water solution with further ultrasonic treatment in a disintegrator. Figure 1 shows the integral precipitation curve.

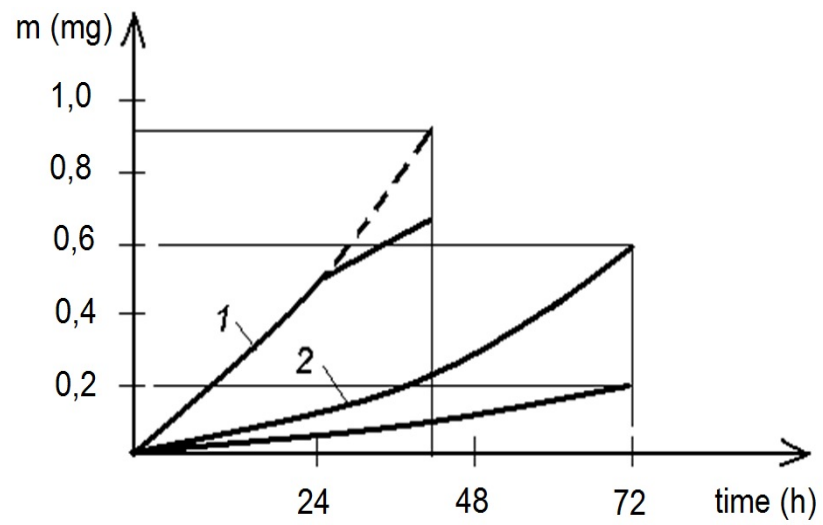

Figure 1. Integral precipitation curve:

CNTs - water; 2) CNTs, water as a plasticizer; 3) $\mathrm{OH}-\mathrm{CNTs}$, water as a plasticizer.

It is pretty complicated to assess the quality of the produced nanocomposite either by homogeneity factor or by heterogeneity factor. Besides, the use of either zeta potential or permeability coefficient does not provide accurate results, and most significantly, it cannot be considered a rapid test method.

The impact of nanomodifiers on the gypsum binder hydration process was investigated by exploring temperature changes 
of the system (building gypsum + water + plasticizer + CNTs, heat release), $\mathrm{pH}$ variations, and structure formation rate (conversion of $\left.\mathrm{CaSO}_{4} \cdot 0,5 \mathrm{H}_{2} \mathrm{O} \rightarrow \mathrm{CaSO}_{4} \cdot 2 \mathrm{H}_{2} \mathrm{O}\right)[9-11]$.

During the calorimetric tests, calcium sulfate hemihydrate particles were gaged with water and mixed. Test conditions were as follows: regardless of dilution by water, the original binder particles were separated by small spaces, and ions passing into the solution had no time to move over large distances due to diffusion hindrance in the liquid phase.

When adding CNTs an accelerated hydration reaction was observed. This occurs because of intensive crystallization of $\mathrm{CaSO}_{4} \cdot 2 \mathrm{H}_{2} \mathrm{O}$ due to adding a nanomodifier of high specific surface area and reactivity.

\section{Results and discussion}

The results of measurements (Figure 2) of heat generation rate during calcium sulfate hemihydrate hydration indicate that there is an opportunity to perform technical control through production processes in order to obtain target properties of a material.

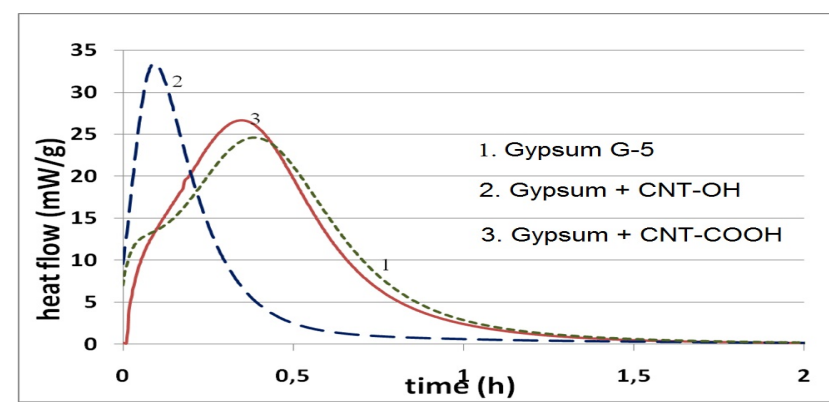

Figure 2. Relationship between heat generation rate during the calcium sulfate hemihydrate hydration process and a type of nanomodifier.
According to research conducted by Marilena Carbone [9], $\mathrm{Ca}^{2+}$, sorption on the graphene surface of CNTs results in an increased oversaturation degree of the nearsurface solution.

This facilitates more complete and rapid conversion of calcium sulfate hemihydrate to dihydrate, and hence, accelerates the calcium sulfate dihydrate crystallization process. Thus, thermodynamic curves are representative of achievability of solidification processes in conjunction with the achievement of the target technological characteristics, namely, strength, setting time, etc.

X-ray powder diffraction allows for obtaining highly accurate information on quantitative and qualitative phase composition of a material in a short period of time.

During the research with the use of $\mathrm{X}$ ray diffractometer X'Pert PRO MPD 3040/60 Fa. PANalytical (Institute of Ceramics, Glass and Construction Materials [IKGB TU Bergakademie Freiberg]), the original gypsum binder and building gypsum-based samples both non-modified and modified with carbon nanotubes were analyzed (Table 1).

Table 1.

\begin{tabular}{|c|c|c|c|c|c|}
\multicolumn{7}{|c|}{ Phase concentration, \% Wt } \\
\hline & $\begin{array}{c}\mathrm{CaSO}_{4} \cdot \\
0,5 \mathrm{H}_{2} \mathrm{O}\end{array}$ & $\begin{array}{c}\mathrm{CaSO}_{4} \cdot \\
2 \mathrm{H}_{2} \mathrm{O}\end{array}$ & $\mathrm{CaSO}_{4}$ & $\begin{array}{c}\mathrm{CaC}^{2} \\
\mathrm{O}_{3}\end{array}$ & $\mathrm{C}$ \\
\hline $\begin{array}{c}\text { Gypsum } \\
\text { binder }\end{array}$ & 91 & 3 & 4 & 2 & - \\
\hline $\begin{array}{c}\text { Building } \\
\text { gypsum }\end{array}$ & 3 & 88 & 4 & 2 & - \\
\hline $\begin{array}{c}\text { Building } \\
\text { gypsum } \\
+ \text { CNTs }\end{array}$ & 1 & 93 & 3 & 2 & $\begin{array}{c}1 \\
(0.05\end{array}$ \\
\hline
\end{tabular}


The following materials were used as structural models of mineral components for the full-profile quantitative X-ray phase analysis: gypsum $\mathrm{CaSO}_{4} \cdot 2 \mathrm{H}_{2} \mathrm{O}$ (PDF No. 01-074-1433), bassanite $\mathrm{CaSO}_{4} \cdot 0,5 \mathrm{H}_{2} \mathrm{O}$ (PDF No. 01-0811849), anhydrite $\mathrm{CaSO}_{4}$ (PDF No. 01-0862270), and carbon C (PDF No. 01-075-2078). The duration of each cycle was $5 \mathrm{~min} .16 \mathrm{sec}$. The hydration process was completed at the $18^{\text {th }}$ cycle, i.e., upon the expiration of 95 minutes; the amount of $\mathrm{CaSO}_{4} \cdot 2 \mathrm{H}_{2} \mathrm{O}$ was $88 \%$.

We also conducted the X-ray diffraction analysis to research hardening of non-modified and modified samples of gypsum binders. Figures 3 and 4 contain the results of calculations of the original gypsum binder sample and the sample modified with CNTs.

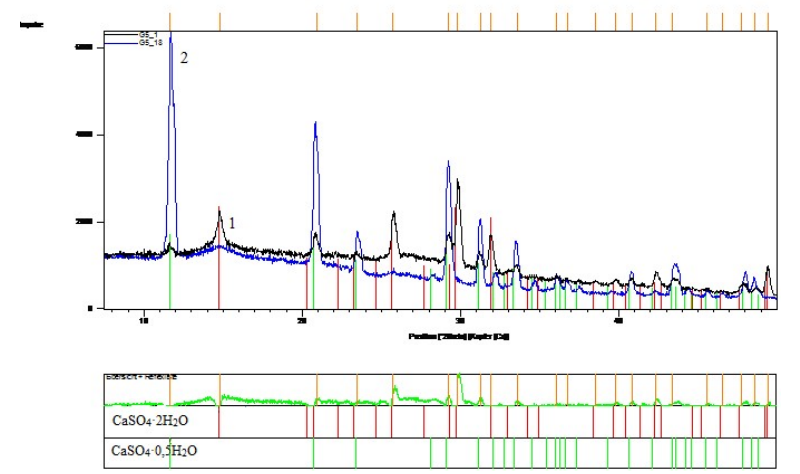

Figure 3. Rietveld diagram of gypsum hardening through time.

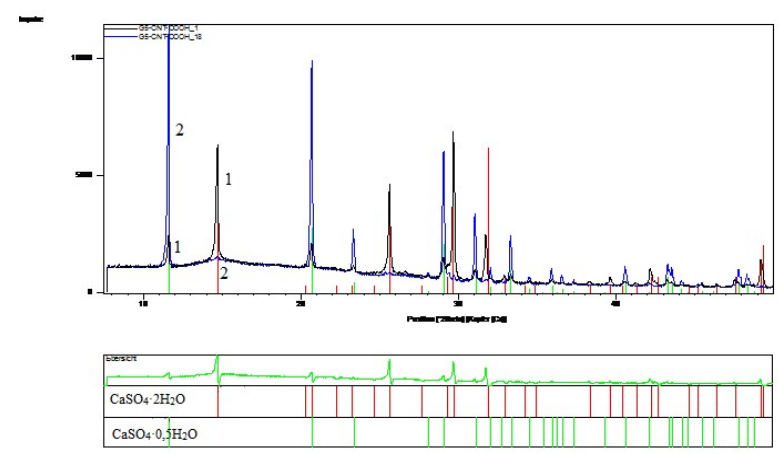

Figure 4. Rietveld diagram of CNT-modified gypsum hardening through time.
The X-ray photograph of the gypsum sample at the $1^{\text {st }}$ cycle (Figure 3, Curve 1) shows that there is a large amount of calcium sulfate hemihydrate (93\%) and a small amount of calcium sulfate dihydrate (up to $3 \%$ ). The duration of each cycle was 5 min. $16 \mathrm{sec}$. The hydration process was completed at the $18^{\text {th }}$ cycle (Figure 3, Curve 1), i.e., upon the expiration of 95 minutes. Main impulses of intensity of the reflected lines of calcium sulfate dihydrate correspond to 6200,4250 , and 3300 .

Data from the X-ray photograph of CNT-modified gypsum binder hardening are indicative of the intensification process of the hydration processes. The hydration process was also completed at the $18^{\text {th }}$ hardening cycle (upon the expiration of 95 minutes); however, calcium sulfate dihydrate formation rate was considerably higher. The lines of main impulses of calcium sulfate dihydrate correspond to 11300, 9900, 6000 (Figure 4).

During the hydration of non-modified building gypsum within 18 cycles (95 minutes), the process was running with the formation of $\mathrm{CaSO}_{4} \cdot 2 \mathrm{H}_{2} \mathrm{O}$ in the amount of up to $88 \%$. Under the same conditions, the hydration of modified gypsum reached $93 \%$, and the amount of unreacted $\mathrm{CaSO}_{4}$ even slightly dropped (Table 1).

The conversion of calcium sulfate hemihydrate to dihydrate has not been completed by the end of two hours as compared to modified gypsum. In addition, the calculation 
shows an increase in the amount of calcium sulfate dihydrate (from 88 to $93 \%$ ).

Based on the data from both the quantitative X-ray photographs and progress $\mathrm{X}$ ray photographs, we can make a conclusion that the addition of CNTs provides the enhanced hydration process, more complete conversion of calcium sulfate hemihydrate to dihydrate, and improvement of physical and mechanical properties of the calcium sulfate matrix.

The analysis of the modified binder structure does not allow us to identify the impact pattern of the nanomodifier, though electronic photomicrographs show certain changes (Figure 5) (the number of electronic photomicrographs related to one series only is 85 items, Germany).
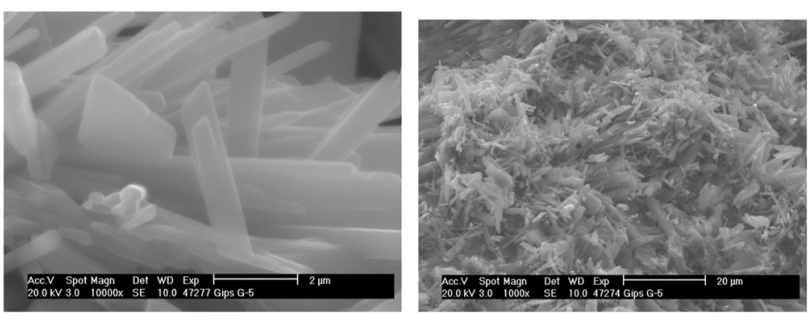

a)
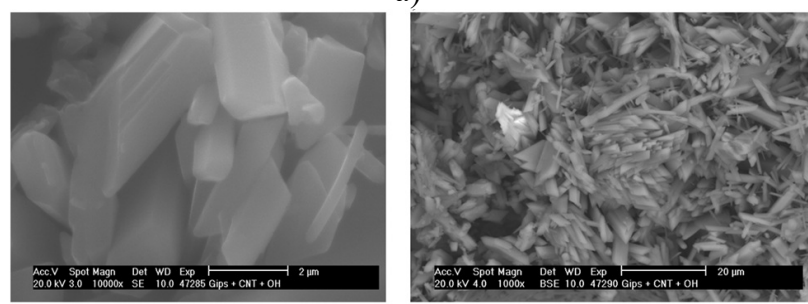

b)
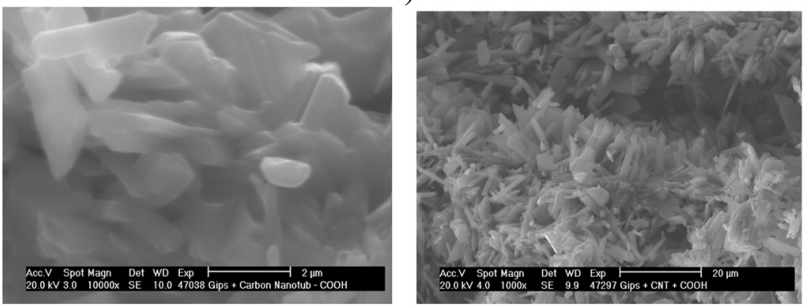

c)

Figure 5. Photomicrographs of gypsum composition: a) without adding CNTs; b) with the addition of CNTs; c) with the addition of $\mathrm{COOH}-\mathrm{CNTs}$.
Moreover, the analysis of the microstructure of the gypsum composition samples has shown that the addition of the modifier facilitates structure consolidation (Figure 5 b, c).

According to A.A. Plugin and H.-B. Fisher [12], structure strength and water resistance during mineral binder hardening is ensured by strong electrostatic attraction of electric double layers of the particles. When adding a mineral additive with negative electric surface charge and electric surface potential calcium sulfate dihydrate crystals grow from the surface of the particles and fill the gaps. This provides additional improvement of water resistance.

The research conducted to evaluate ultimate bending strength and ultimate compressive strength of the test beams at 2 hours has shown that an increased content of the nanoadditive causes the improvement of structural characteristics of the composite material (Table 2).

Table 2. Properties of gypsum binder modified by multi-walled CNTs with functional groups

\begin{tabular}{|c|c|c|c|c|c|c|c|}
\hline No & $\begin{array}{c}\text { Surfacta } \\
\text { nt, } \%\end{array}$ & $\begin{array}{c}\text { CNT } \\
\text { s, } \%\end{array}$ & $\begin{array}{c}\text { W/G } \\
, \%\end{array}$ & $\begin{array}{c}\text { Setting } \\
\text { time, } \\
\text { min }\end{array}$ & \multicolumn{2}{|c|}{ Strength, MPa } \\
\cline { 5 - 9 } & & $\begin{array}{c}\text { St } \\
\text { art }\end{array}$ & $\begin{array}{c}\text { E } \\
\text { nd }\end{array}$ & $\begin{array}{c}\text { Compre } \\
\text { ssion }\end{array}$ & $\begin{array}{c}\text { Bend } \\
\text { ing }\end{array}$ \\
\hline \multicolumn{7}{|c|}{ COOH } \\
\hline 1 & 0.4 & - & 58 & 16 & 24 & 5.5 & 3.2 \\
\hline 2 & 0.4 & 0.015 & 58 & 9 & 13 & 8.0 & 3.85 \\
\hline 3 & 0.4 & 0.035 & 58 & 8 & 13 & 8.1 & 3.6 \\
\hline 4 & 0.4 & 0.09 & 58 & 8 & 12 & 8.45 & 3.95 \\
\hline 5 & 0.4 & 0.18 & 58 & 11 & 17 & 7.86 & 3.6 \\
\hline & & & $-\mathbf{O H}$ & & \\
\hline 1 & 0.4 & - & 58 & 16 & 24 & 4.6 & 2.1 \\
\hline 2 & 0.4 & 0.015 & 58 & 9 & 13 & 5.6 & 2.2 \\
\hline 3 & 0.4 & 0.035 & 58 & 8 & 13 & 5.9 & 2.2 \\
\hline
\end{tabular}


Strength properties have been improved by up to $30 \%$. Water resistance: softening coefficient has been 0.3 to $0.5-0.6$ on average.

When describing the impact of carbon surface on the structure of a molecule of calcium sulfate dihydrate it is worth paying attention to the gypsum hydration model based on Le Chatelier's principle. When interacting with water calcium sulfate hemihydrate dissolves and solution saturated with $\mathrm{Ca}^{2+}$ and $\mathrm{SO}^{2-}$ ions is formed. Solubility of $\mathrm{CaSO}_{4} \cdot 0,5 \mathrm{H}_{2} \mathrm{O}$ is four times higher than that of $\mathrm{CaSO}_{4} \cdot 2 \mathrm{H}_{2} \mathrm{O}$. Therefore, the liquid phase creates favorable conditions for the formation of nuclei of $\mathrm{CaSO}_{4} \cdot 2 \mathrm{H}_{2} \mathrm{O}$ crystals and their precipitation from solution. This promotes a lower concentration of both $\mathrm{Ca}^{2+}$ and $\mathrm{SO}^{2-}$ ions and creates conditions for the dissolution of new additions of the original substance.

The assessment of the interaction between a calcium sulfate dihydrate molecule and the CNT surface has shown that the molecule tends to chemical interaction with the surface [2] through a calcium ion (Figure 6).

The calculations made have shown that the chemical interaction of $\mathrm{CaSO}_{4} \cdot 2 \mathrm{H}_{2} \mathrm{O}$ molecule with the graphene surface results in a significant change in the charge of $\mathrm{Ca}^{2+}$ ion (by approximately $16 \%$ as compared to the initial charge) and a slight change in the charges of other atoms by not more than $2 \%$. Thus, we can come to a conclusion that there is a slight change in the chemical reactivity of peripheral atoms of a molecule which are involved in intermolecular interactions in a calcium sulfate dihydrate crystal.

a)

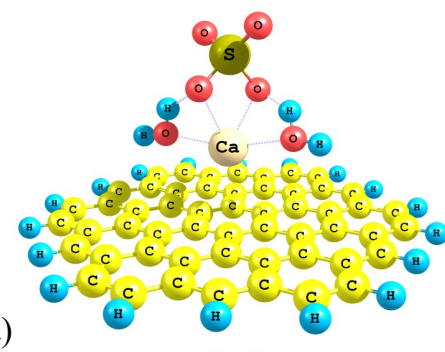

b)

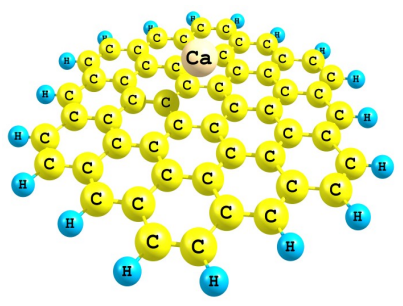

Figure 6. Pattern fragments of the CNT surface which interact with:

a) - gypsum molecule; b) $\mathrm{Ca}^{2+}$ ion.

The interaction of a calcium sulfate dihydrate molecule with the graphene surface has been proved by the methods of quantum chemical analysis. The improved strength properties of the CNT-modified gypsum binder have been achieved due to the accelerated processes of calcium sulfate dihydrate crystallization close to the graphene surface.

\section{Conclusions}

Gypsum modification by multi-walled CNTs results in the improvement of its compressive strength. It has been experimentally proved that the content of nanotubes of $0.18 \%$ results in an increase in strength by up to $30 \%$.

Chemical functionalization of the surface of carbon nanotubes promotes a reduced sedimentation effect inherent to nanoparticles; 
moreover, it makes it possible to achieve a more uniform nanostructure dispergation throughout the modified material volume and provides chemical interaction between the substance matrix and nanotubes.

Interaction of a calcium sulfate dihydrate molecule with the graphene surface is a chemical process, which has been proved by the methods of quantum chemical analysis. The improvement of CNT-containing gypsum composite strength is due to the accelerated process of calcium sulfate dihydrate crystallization close to the graphene surface. Thus, it may be assumed that CNTs function as 'crystallization nuclei' in a gypsum composite.

Based on the data from both the quantitative $\mathrm{X}$-ray photographs and progress $\mathrm{X}$ ray photographs, we can make a conclusion that the addition of CNTs provides the enhanced hydration process, more complete conversion of calcium sulfate hemihydrate to dihydrate, and improvement of physical and mechanical properties of the calcium sulfate matrix.

The analysis of the microstructure of the gypsum composition samples has shown that without adding the modifying additive, a porous open-grain structure of the gypsum samples is formed with a significant number of pores.

It may be assumed that nanodispersed CNT additives function as 'crystallization nuclei' on the surface of which calcium sulfate matrix structuring occurs with the improvement of structural characteristics of the gypsum composition. It is related to the fact that during growth, crystals partly penetrate into each other and form a three-dimensional network permeating and incorporating the entire gypsum stone into a whole body.

\section{Acknowledgements}

Victor Derevianko would like to express his appreciation to the Freiberg Mining Academy (Institute of Ceramics, Glass and Construction Materials (IKGB TU Bergakademie Freiberg)) for the financial support and opportunity to conduct the research.

\section{References}

[1] Chumak A.G., Derevianko V.N., Petrunin S.Yu., Popov M.Yu., Vaganov V.E. Structure and properties of a composite material based on gypsum binder and carbon nanotubes. J. Nanotechnology in Construction 2013; 2:27-37. Available at: http://nanobuild.ru/en_EN/journal/Nanobuild-2-2013/2737.pdf

[2] Reshetnyak V.V., Vaganov V.E., Petrunin S.Yu., Chumak A.G., Popov M.Yu. Interaction of calcium ions with carcass carbon structures. J. Construction, Materials Science, Mechanical Enginering 2013;67:261-266.

[3] Petrenko D.B. Modified Boehm's method for the determination of hydroxyl groups in carbon nanotubes. Electronic Journal "Bulletin of the Moscow State Regional University”, Chemistry 2012; 1 Available at: http://evestnik-mgou.ru/ru/Articles/Doc/168

[4] Habachesku V.N., Grigoryeva Ye.E. Covalent functionalization of carbon nanotubes: synthesis, properties and use of fluorinated derivatives. J. Achievements in Chemistry 2011; 80(8): 739-760. Available at: https://elibrary.ru/item.asp?id=16521993

[5] Yakovlev G.I., Pervushyn G.N., Korzhenko A., Buryanov A.F., Pudov I.A., Lushnikova 
A.A. Modification of cement concretes with multi-walled carbon nanotubes, J. Constr. Materials 2011;2:47-51.

[6] Badamshyna E.R., Gafurova, M.P. Estrin, Ya.I. Modification of carbon nanotubes and synthesis of polymer composites involving carbon nanotubes. J. Achievements in Chemistry 2010; 79(11):1028 - 1064 Available at: http://www.turpion.org/php/paper.phtml?journal_id=rc\&p aper id $=4114$

[7] Yudovich M.E., Ponomaryov A.N., Gareyev S.I. Surface active properties of nanomodified plasticizers, J. Construction Materials 2008; 3:2-3.

[8] Morsy M., Elkhodary S.A., Shebl S.S. Synthesis and characterization of thermally stable carbon nanotubes using the ARC-Discharge technique, J. Construction Materials: Reports of the $\mathrm{V}$ International conference "Nanotechnology for Green and Sustainable Construction", March 23-25, Cairo. 2012; 2:44-47. Available at: http://rifsm.ru/u/fl/itm5717.pdf

[9] Carbone Marilena, Ballirano Paolo, Caminiti Ruggero. Kinetics of gypsum dehydration at reduced pressure: an energy dispersive X-ray diffraction study. European Journal of Mineralogy 2008; 20(4): 621 - $627 . \quad$ Available at: https://www.schweizerbart.de/papers/ejm/detail/20/58188 /Kinetics_of_gypsum_dehydration_at_reduced_pressure an_energy_dispersive_X_ray_diffraction_study

[10] Lager G.A., Armruster Th., Rotella F.J., Jorgensen J.D., Hinks D.G. A crystallographic study of the low-temperature dehydration products of gypsum, $\mathrm{CaSO}_{4} 2 \mathrm{H}_{2} \mathrm{O}$ : hemihydrate $\mathrm{CaSO}_{4} 0.5 \mathrm{OH}_{2} \mathrm{O}$, and $\gamma-\mathrm{CaSO}_{4}$, J. American Mineralogist 1984; 69:910 - 918. Available at: http://ammin.geoscienceworld.org/content/69/9-10/910

[11] Bushuyev N.N. On structural peculiarities of $\mathrm{CaSO}_{4}$, The Proceedings of the USSR Academy of Sciences. Section "Crystallography". 1980; 255(5): 1104-1109. 